\title{
From Scale to Norm to Excellence-Higher Vocational Education Policy-Making and Progress in China
}

\author{
Hua Huang \\ Nanjing Polytechnic Institute, Jiangsu, China \\ Rong Ma \\ Nanjing Normal University, Jiangsu, China
}

\begin{abstract}
Great achievements and unique advantages have been made after 40 years of development of higher vocational and technical education in China. The development goes through three stages, including start-up stage to build up the vocational higher education system from nothing, expansion stage to promote scale expansion of the higher voacational education, and innovation stage to highlight the characteristics development of higher vocational education. In the third stage, three important construction programs have been implemented to push forward the development of higher vocational education in China. Through literature review, data analysis, and other research methods, it is found that the relevant policies were made in the different development stages, which have effectively led the development of higher vocational and technical education in China from scale expansion to standardized operation, to model innovation, then to improving quality and striving for excellence. That is rightly the cooperative effort of the guidance of national policies and creation of most colleges which prompt the developing trend of higher vocational and technical education in China.
\end{abstract}

Keywords: scale, standardization, excellence, higher vocational education, policy-making

China's higher vocational education goes with the development of 40 years of reform and opening up of China. Thirteen short-term vocational universities established in 1980 are the predecessor of China's higher vocational education. It developed from nothing, from small to large scale, then to excellence. Currently, it takes half of the China's higher education. Until 2016, there are 1,359 vocational colleges with more than 10 million students at school (Ministry of Education of the People's Republic of China, 2017), and at least one vocational college establishes in over $95 \%$ of cities in China, forming the world's largest higher vocational education, and becoming an important component of the original development of the national education system and human resources. In the 40 years of development of higher vocational education in China, at each important turning point, a series of policies and regulations have been introduced to guide, promote, and guarantee the healthy and rapid development of higher education. From the perspective of policy analysis, the study will sort out the policy changes in China's higher vocational education according to policy analysis, policy background, and policy implementation.

Corresponding author: Hua Huang, Ph.D., professor, Nanjing Polytechnic Institute, Jiangsu, China; research fields: higher education internationalization, comparative education.

Rong Ma, Ph.D. student, associate professor, Nanjing Normal University, Jiangsu, China; research fields: comparative education, higher education internationalization. 


\section{Start-up Stage (1980-1998): Building up Higher Vocational Education System From Nothing}

The policy orientation of the vocational education system at this stage is to clarify the position of higher vocational education in the national education system and to establish a vocational education system from the perspective of law. In China's higher education system, there is no such type of occupational instruction. At the beginning of China's reforms and opening up, the economy and culture were relatively backward. The development of various small and medium-sized enterprises and township enterprises urgently need a large number of technical talents who could meet the needs for the basic production. Just passed Cultural Revolution, higher education made a great destruction caused a shortage of productive talents. In order to meet the needs of the country's most urgent economic and educational development, the short-term vocational university developed rapidly, and became the original form of higher vocational education in China.

From 1985 to 1986, the Central Government issued a series of decisions and regulations, including "The Chinese Communist Party's Decision on the Reform of the Education System", "The Provision on the Administration of Higher Education", and "Provisional Regulations on the Establishment of Institutions of higher Education", which made a clear regulation about the establishment of the institutes. Meanwhile, it proposed that "part of the high school graduates should enter into the general universities, and part of graduates into higher vocational colleges to actively develop the higher vocational education". Higher vocational education, developed from nothing, has been included into the national higher education system. Till 1989, 117 vocational universities had been built with the total number of students increasing to 297,000, which was close to the number of undergraduate students of that year. The total number of college students has increased to 760,000 , accounting for 36 percent of the total student number in higher education.

The Article 13 of the Vocational Education Law of the People's Republic of China, issued in 1996, defines that "vocational school education include primary, secondary, and higher-level school education" (The Central People's Government of the People's Republic of China, 2005). The Article 68 of the Higher Education Law of the People's Republic of China, issued and implemented in 1998, regulates that "the higher education institutes refer to the university, independently established colleges and higher vocational colleges, including higher vocational schools and adult higher education" (Yang, 2011, p. 467). According to the available information, at present, there are only two countries in the world that have clearly defined higher vocational education and implemented it in legislation. One is China, which was established by legislation in 1996, and the other is Switzerland in $2004^{1}$.

\section{Expansion Stage (1999-2005): From Small to Large, to Promote Vocational Education Scale Expansion}

The policy at this phase is to implement the requirements of the national popularity of higher education, and to promote vocational education scale expansion, while improving teaching quality. China's higher education has always been elite education, which is in a too small scale. Since the reform and opening up, there has been a serious shortage of supply of highly-utilized people needed by small and medium-sized enterprises that are springing up. The Chinese people who have solved their problems of food and clothing have shown great desire for higher education. Coupled with the other factors, China at the turn of the century has made a

\footnotetext{
${ }^{1}$ Staatssekretariat für Bildung, Forschung und Innovation SBFI. Das Berufsbildungsgesetz (BBG). [EB/OL]. 1. January 2004.
} 
major strategic decision to promote the popularization of higher education, which is marked by vigorous development of higher vocational education.

In January 1999, the Ministry of Education and the State Development Planning Commission jointly issued the "Implementation Opinions on Implementing Higher Vocational and Technological Education in Accordance with New Management Models and Operating Mechanisms". It is clearly stated that higher vocational education is implemented by the following institutions: short-term vocational colleges, vocational technology colleges, private institutions with qualifications for higher education, higher vocational institutions set up in undergraduate university (secondary colleges), a handful of state-level key secondary specialized schools approved by the Ministry of Education, and adult colleges and universities that meet the required standards of running schools. The focus of this policy is to delegate approval authority to set higher vocational colleges, fully arouse the enthusiasm of the local school running, which has a far-reaching significance in promoting China higher vocational education. In 2005, there are 1,091 higher vocational colleges in China, accounting for $60.8 \%$ of the total number of higher education institutions, with 7.13 million students in higher vocational colleges, accounting for $45.69 \%$ of the total number ( $\mathrm{Li}, 2006)$.

As the rapid expansion of the scale, policy-making begins to take care about the insufficient teaching facilities, inadequate teachers, and the quality of personnel cultivation, such as, Opinions on Strengthening the Talents Cultivation in Higher Vocational Education in 2000 and Opinions on the Employment-oriented Reform of Higher Education in 2004. In 2004, the Ministry of Education initiated the evaluation of the talent cultivation in higher vocational colleges, which called for "strengthening the basic construction of teaching, deepening the education and teaching reform" (Ministry of Education of the People's Republic of China, 2015a). The main objective is to evaluate the "input quality" in order to promote the hardware conditionsof higher vocational colleges. That is to say, newly established higher vocational colleges began to shift from focusing on scale expansion to standardizing on running schools.

\section{Innovation Stage (2006-2018): From Large to Excellent, Highlighting the Characteristics Development of Higher Vocational Education}

At this stage, the policy-making is to encourage vocational colleges to make exploratory practice and lead the development of higher vocational education, so as to promote the unique development. After about 20 years' exploration and huge development at the turn of the century, the scale effect of higher vocational education has been initially demonstrated. Under such a background, how can we realize the transformation of higher vocational education from large-scale to excellence? Therefore, from 2006 to now, the Ministry of Education of the People's Republic of China has launched three rounds of project construction which aim at exploring the practice to accumulate experience, and forming a prototype to establish a benchmark for development.

\section{The National Model Construction Program for Higher Vocational Colleges: Guiding the Work-Study Combination Reform of the Talent Cultivation Model}

After the "Decision of the State Council on Developing Qualified Vocational Education" in 2005, the "Development Plan for National Model Higher Vocational Colleges, Opinions on Accelerating the Reform, and Development of Higher Vocational Education (hereinafter abbreviated as No. 14 Document)" was issued in 2006, which started the construction plan for the national model vocational colleges. It selected a total of 100 vocational colleges and provided support in three consecutive years. Through the model colleges construction 
program, a group of strong vocational colleges with distinct characteristics develop rapidly, so as to promote the general development of higher vocational schools nationwide. The Guidelines on Enhancing the Teaching Quality of Higher Vocational Education in an All-round Way (hereinafter referred to as No. 16 Document) is to promote the overall improvement of the quality of higher vocational education. No. 16 Document requires that educational administrative departments at all levels and higher vocational colleges should "appropriately control the growth rate of school enrollment...effectively focus on quality improvement; actively cooperate with industry and enterprises to do curriculum development, and involve employers to make education evaluation" (Ministry of Education of the People's Republic of China 2006).

It has been proved that the joint publication of the two documents has played a decisive role in promoting China's higher vocational education from the large-scale to the excellence. After this period of adjustment, the ultra-normal development of higher vocational colleges has been fundamentally reversed. The number of newly established higher vocational institutions every year has dropped from 166 at the peak to 28 in 2009, and the growth rate of student enrollment decreased from $20.7 \%$ in the previous stage to $0.9 \%$ in 2009 (Ministry of Education of the People's Republic of China, 2012).

There has been a great improvement of model colleges in running schools, teaching quality, management, operating efficiency, and radiating capacity. The focus is on the specialty construction with work and study combination. The central government provides five million RMB to each out of 500 specialties from demonstrative colleges. Through this, a number of key specialties were built as the professional talent curriculum and connected well with the keyindustries around the country, which has effectively promoted the development of a large number of vocational colleges at the provincial level or in the industrial fields. The special investment of the central finance has produced obvious pull-effect, the local finance has greatly increased and promoted the development of higher vocational colleges. The level of budget allocation for students has been obviously improved.

\section{The National Backbone Construction Program for Higher Vocational Colleges: Mechanism Innovation of School-Enterprise Cooperation}

In 2010, on the basis of fully accrediting the achievements of the National Model Higher Vocational School Construction Program, another document of "About Further Promote the Implementation of the National Model Higher Vocational College Construction" was issued, and made a decision that 100 new backbone vocational colleges would be financially supported in the next three years, which would continue to play a guiding role through financial support in the reform and development of higher vocational education (Ministry of Education of the People's Republic of China, 2010). In the National Backbone Construction Program, mechanism innovation, environmental policies, faculty resources, and service capabilities found during the process of demonstrative colleges construction were paid special attention for the National Backbone Construction Program. The focus of the reform is on the innovation of institutional mechanisms for school-enterprise cooperation, and central financial support is 20 billion RMB. After the completion of the construction program, $90 \%$ of backbone colleges established the School-Enterprise Cooperation Council, or vocational education group. All key specialties set up the Professional Construction Guidance Committee, and part of specialty explored the upgrading model of school-enterprise cooperation.

For example, the Specialty Group of Communication in Nanjing Institute of Information Technology has established a new school-enterprise cooperation model, "cooperate with upstream companiesin the technology 
chain to build a public technology service platform, and cooperate withdownstream companies to provides graduates and training services", which is the upgrading model of school-enterprise cooperation.

The public technology service platform integrates the advanced technical requirements for the development of the communications into teaching and training. Engineers from industry and college teachers set up a working team to teach and provide training and technological service according to the same standards, which has been highly recognized and welcomed by companies in the industries (Ma, 2017).

Just because the exploratory try and practice, a series of supporting policies were introduced by the local government, including school-enterprise cooperation, teacher professional and technical job evaluation, internship subsidies, part-time teacher subsidies, consumptive material subsidies for training, etc. All those new innovative experience of backbone schools has become the institutionalized achievements, and optimized the overall development environment of higher vocational education.

\section{The High-Quality Construction Program for Higher Vocational Colleges: Guiding the High-Level Specialty Construction With the Integration of Industry and Education}

In 2014, the National Vocational Education Work Conference was held. In 2015, "Innovation Development Action Plan of Higher Vocational Education (2015-2018)" (hereinafter referred as the "Action Plan") was issued, which started the high-quality construction of vocational colleges and universities, with the focus on production and education combination. The Action Plan carries the following work as the major construction tasks, including "strengthen the educational reform, enhance the technical innovation service capabilities, develop outstanding technical talents, strengthen the reputation of teachers and graduates in the industries, improve the school's contribution to industrial developmentcore, and strive for an international advanced development" (Ministry of Education of the People's Republic of China, 2015b). The Action Plan, for the first time, clearly stated that "explore vocational education in general undergraduate education, recruit the students in this field to a certain number, make a periodical achievement of occupation-oriented postgraduate education of professional degree reform". Meanwhile, international influence of vocational higher education is stressed, and it is put forward that "supporting high-quality vocational colleges to contend for mechanism of advanced international standards. China's higher vocational education keeps expending its international influence, and strengthening its global voice" (Ministry of Education of the People's Republic of China, 2015b). China, with the world's largest and most advanced higher vocational education, must be able to make a unique and irreplaceable contribution to the world's education (Jiang, 2015).

The development model has always adopted two major themes of policy push and innovative development. The policy-push development model focuses on top-down system transmission, while internal innovation and development model emphasize the bottom-up innovation motivation. On one hand, the country continuously standardizes the behaviors of higher vocational institutions, clarifies the objectives for talent training, and perfects the institutional mechanisms, in terms of issuing policies, setting up projects, and conducting educational assessments.

The investment of the the central government has taken the leverage effect. Since 2005, from progressive relationship among the policies of three programs, the National Model Construction Program focuses on the work-study combination, the National Backbone Construction Program on the innovation of mechanism for school-enterprise cooperation, and the High-Quality Construction Program on overall educational quality of integration of enterprises with vocational schools and universities. Work-study combination is adopted in terms 
of teaching and learning, school-enterprise cooperation is in terms of school-running, and industry-school integration is in management level.

On the other hand, during the implementation of each project, institutional innovation and model innovation, coming from the local government and the higher vocational colleges and universities, provide a good demonstration for the entire country, making clear for the next focus of the development and goals and visions. Just with the combination of top-down policy push and bottom-up innovation, China' a higher vocational education can continuously solve problems and bottlenecks, to realize the trans-normal strategical leading development.

\section{Conclusions}

Educational mechanism of China's higher vocational education entitled with "Government-led", "Market Mechanism", and "Autonomous School Running", with the theme of "Industry-school integration, school-enterprise cooperation, work-study combination, and learning by doing", is coming into being. The development of the higher vocational education changes the overall structure of higher education in China, which becomes the important power to promote the economic development, employment and entrepreneurship, and educational equality. China's higher vocational education not only supplies abundant talents for the past 40 years, but also greatly improves the quality of the whole people. The higher vocational education is an important part of human resources as well as the national educational system, which significantly distinguishes China from the other major developed countries. It is believed that the higher vocational education will take far-reaching development superiority.

\section{References}

Jiang, D. Y. (2015). On the unique contribution of Chinese higher vocational education to world education. Chinese Professional Skills Education, 36, 10-18.

Li, Z. H. (2006). Do a good job in the assessment work to promote the healthy development of higher vocational education. Chinese Professional Skills Education, 16, 5-7.

Ma, S. C. (2017). The integration of production and education: From demonstration to the construction of quality colleges and universities mainline. Vocational and Technical Education Forum, 1, 32-35.

Ministry of Education of the People's Republic of China. (2006). Some opinions on improving the teaching quality of education in higher vocational education. Department of Higher Education, Ministry of Education.

Ministry of Education of the People's Republic of China. (2010). Notice on further promoting the implementation of "national demonstration higher vocational college construction plan". Department of Higher Education, Ministry of Education.

Ministry of Education of the People's Republic of China. (2012). Annual education report on higher professions in China (2009). Department of Higher Education, Ministry of Education. Retrieved from http://wenku.baidu.com/view/febbc5146c175f0e7 cd1373e.html

Ministry of Education of the People's Republic of China. (2015a). Notice concerning the comprehensive evaluation of talent cultivation in vocational colleges. Retrieved from http://old.moe.gov.cn/publicfiles/business/htmlfiles/moe/moe_42/ 200409/1182.html

Ministry of Education of the People's Republic of China. (2015b). Notification on the issuance of the higher professions education action plan for innovative development (2015-2018). Department of Vocational Education and Adult Education, Ministry of Education.

Ministry of Education of the People's Republic of China. (2017). 2016 National education career development statistical bulletin. Retrieved from http://www.moe.gov.cn/jyb_sjzl/sjzl_fztjgb/201707/t20170710_309042.html

The Central People's Government of the People's Republic of China. (2005). The law of the People's Republic of China on vocational education. Retrieved from http://www.gov.cn/banshi/2005-05/25/content_928.htm

Yang, J. S. (2011). Significant change in past 30 years-Outline of education career in China from 1979 to 2008. Beijing: Education Science Press. 